\title{
Performance and Vibration Analyses of Lift-Offset Helicopters
}

\author{
Jeong-In Go, ${ }^{1}$ Do-Hyung Kim, ${ }^{2}$ and Jae-Sang Park ${ }^{1}$ \\ ${ }^{1}$ Department of Aerospace Engineering, Chungnam National University, Daejeon 34134, Republic of Korea \\ ${ }^{2}$ Rotorcraft Research Team, Korea Aerospace Research Institute, Daejeon 34133, Republic of Korea \\ Correspondence should be addressed to Jae-Sang Park; aerotor@cnu.ac.kr
}

Received 20 March 2017; Revised 21 April 2017; Accepted 30 April 2017; Published 15 June 2017

Academic Editor: Davide Micheli

Copyright (C) 2017 Jeong-In Go et al. This is an open access article distributed under the Creative Commons Attribution License, which permits unrestricted use, distribution, and reproduction in any medium, provided the original work is properly cited.

\begin{abstract}
A validation study on the performance and vibration analyses of the XH-59A compound helicopter is conducted to establish techniques for the comprehensive analysis of lift-offset compound helicopters. This study considers the XH-59A lift-offset compound helicopter using a rigid coaxial rotor system as a verification model. CAMRAD II (Comprehensive Analytical Method of Rotorcraft Aerodynamics and Dynamics II), a comprehensive analysis code, is used as a tool for the performance, vibration, and loads analyses. A general free wake model, which is a more sophisticated wake model than other wake models, is used to obtain good results for the comprehensive analysis. Performance analyses of the XH-59A helicopter with and without auxiliary propulsion are conducted in various flight conditions. In addition, vibration analyses of the XH-59A compound helicopter configuration are conducted in the forward flight condition. The present comprehensive analysis results are in good agreement with the flight test and previous analyses. Therefore, techniques for the comprehensive analysis of lift-offset compound helicopters are appropriately established. Furthermore, the rotor lifts are calculated for the XH-59A lift-offset compound helicopter in the forward flight condition to investigate the airloads characteristics of the $\mathrm{ABC}^{\mathrm{TM}}$ (Advancing Blade Concept) rotor.
\end{abstract}

\section{Introduction}

Conventional helicopters have the advantages of vertical take-off/landing and hovering, but their maximum forward flight speed, which is approximately 150-170 knots, is very slow compared to fixed-wing aircraft. Therefore, the research and development of compound helicopters capable of forward flight at a high-speed have been recently conducted in the US and Europe in order to overcome the low-speed flight performance of conventional helicopters.

Compound helicopters use wings and auxiliary propulsions as well as rotors. In particular, the XH-59A (Figure 1), $\mathrm{X} 2$ technical demonstrators, and S-97 Raider developed by Sikorsky are compound helicopters using ABC (Advancing Blade Concept, [1]) rotor. ABC is a technology that enables high-speed forward flight of helicopters, and it uses a counterrotating rigid coaxial rotor. $\mathrm{ABC}$ is named because it is designed to generate the most lift on the advancing blades (Figure 2(b), [2]). In addition, $\mathrm{ABC}$ can be expressed as lift-offset (LOS), which can be calculated by dividing the rolling moment of each rotor by its thrust. Compound helicopters using $\mathrm{ABC}$ rotor have the following advantages. The performance loss of the rotor due to the rolling moment trim can be reduced since the rolling moments for each of the upper and lower rotors are the same in magnitudes and are opposite directions. In addition, it is possible to avoid the dynamic stall that occurs on the retreating side of the rotor disk. Moreover, the lift-to-drag ratio of an $A B C$ rotor can be increased compared with that of conventional helicopters. Therefore, the rotation speed of the rotor can be reduced, and high-speed forward flight is possible [2]. However, one of the disadvantages of the lift-offset compound rotorcrafts is the serious vibration problem during highspeed flight. In case of the XH-59A helicopter, flight test results showed serious 3P cockpit vibration during highspeed forward flight due to the rigid coaxial rotor and the absence of a vibration control system [3]. Therefore, both performance and vibration analyses are important when developing compound rotorcrafts using a rigid coaxial rotor. However, few studies using comprehensive analysis codes for performance and vibration analyses have been conducted, despite the development of lift-offset compound helicopters 


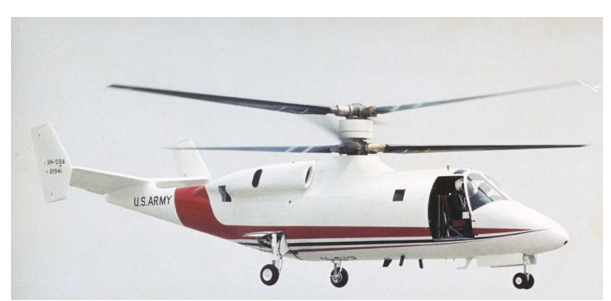

(a) Pure helicopter configuration

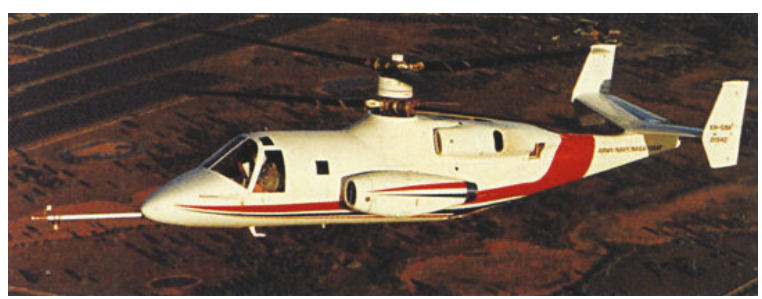

(b) Compound helicopter configuration

Figure 1: XH-59A technical demonstrator.

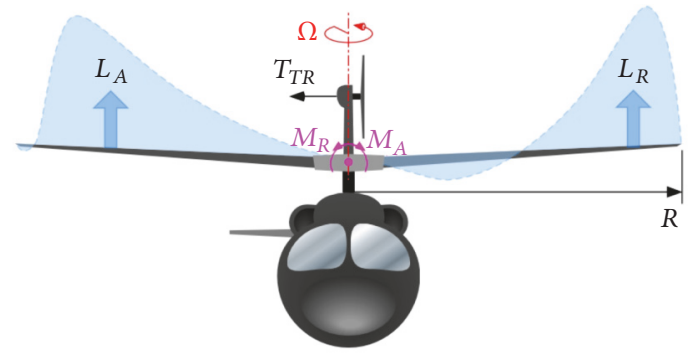

(a) Single main rotor

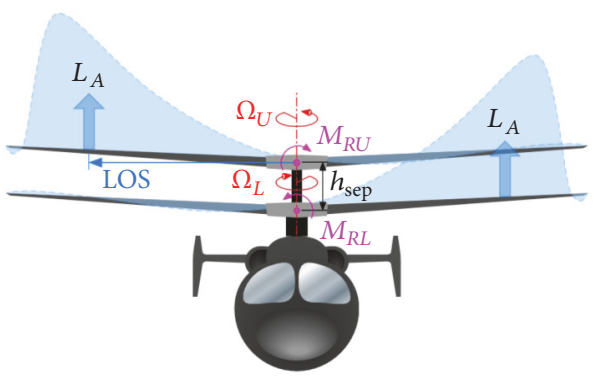

(b) Rigid coaxial rotor with $\mathrm{ABC}$

FIGURE 2: Lift and rolling moment characteristics of conventional single rotor and $\mathrm{ABC}$ rigid coaxial rotor.

such as the XH-59A, X2 technical demonstrators, and S-97 Raider.

Johnson [4] validated the performance analyses of an XH-59A lift-offset compound helicopter using CAMRAD II (Comprehensive Analytical Method of Rotorcraft Aerodynamics and Dynamics, [5]), which is a comprehensive analysis code for rotorcrafts. The free wake model was used only for the analysis in the hover condition, but the prescribed wake model was used for the performance analysis in the forward flight condition. Moreover, a correlation study of the vibration analysis for the $\mathrm{XH}-59 \mathrm{~A}$ helicopter was not conducted in that study [4]. In addition, RCAS (Rotorcraft Comprehensive Analysis System, [6]), a comprehensive analysis code for rotorcrafts, was used in a study of the performance, loads, and vibration of the XH-59A helicopter in the high-speed flight condition [7]. The analysis was conducted to obtain the optimal trim for reduction of total power required of the XH-59A helicopter. In addition, the trim states for low vibration were also studied. However, the analysis results are limited in that most of results of this study [7] were obtained using a finite-state dynamic inflow model, which is relatively simple compared to the free wake model; thus, the validation study on the $3 \mathrm{P}$ pitching moment of the hub was not good. In addition, the analysis of the hover performance was not validated.

Therefore, this study aims to validate and demonstrate a comprehensive analysis using a free wake model for the performance and vibration of the lift-offset compound helicopters. The XH-59A technical demonstrator is considered as the lift-offset compound helicopter for the assessment. In addition, CAMRAD II is used as a tool for the performance and vibration analyses. Unlike previous research, this study uses the general free wake model for the comprehensive analysis in various flight conditions. The free wake model is the most sophisticated wake model than other inflow and wake models. It is important to establish techniques for the comprehensive analysis using the free wake model in order to obtain accurate results for the performance and vibration analyses of lift-offset rotorcrafts by elaborately considering the effect of the rotor wakes. However, compared to other inflow and wake models, it is not easy to determine the parameters of the free wake model, for example, the size of the vortex core. Therefore, a more extensive validation compared to the previous work [7] is conducted using the free wake model for the $\mathrm{XH}-59 \mathrm{~A}$ helicopter with and without auxiliary propulsion in various conditions. In order to validate the modeling and analysis techniques of the comprehensive analysis of the XH-59A helicopter, the results of the performance analysis are compared with both flight test data and a previous analysis [4]. In addition, the vibratory hub loads and the structural loads of the blade of the XH-59A helicopter with auxiliary propulsion are validated with flight test data [8]. Through the present work, techniques for a comprehensive analysis of the lift-offset compound helicopters using a more advanced wake model can be appropriately established. Finally, the lifts for the XH-59A helicopter rotor in the compound helicopter mode are investigated, although these results are not compared with the flight test results.

\section{Validation Model}

This study considers the XH-59A technical demonstrator as a validation model of the comprehensive analysis of the liftoffset compound helicopter. The XH-59A helicopter is an 
ABC technology demonstrator developed by Sikorsky; thus, it can fly at high-speed as well as vertical take-off/landing, hovering, and efficient low-speed flight.

The ABC rotor using a rigid coaxial rotor enables highspeed flight for helicopters and offers several advantages. First, it has a superior hover and low-speed efficiency given that the total power of the coaxial rotor is approximately $5 \%$ less than that of an equivalent single main rotor [9]. Second, an antitorque system such as a tail rotor is not required; thus, it contributes to improve safety and compactness. Third, the lift-offset rotorcraft in the pure helicopter mode is quieter than a conventional helicopter using a single main rotor due to the absence of a tail rotor. However, the rigid coaxial rotor has a heavier rotor, drive, and flight control system. In addition, the high-speed efficiency is poor due to the higher hub drag compared to that of a single main rotor. The liftoffset for the ABC rotor is defined as the rolling moment of each rotor divided by its thrust as follows:

$$
\operatorname{LOS}=\frac{M_{\text {roll }}}{T R}
$$

Prior to the development of the XH-59A compound helicopter with auxiliary propulsion, an XH-59A helicopter using a lift-offset rotor was initially developed as a pure helicopter configuration (Figure 1(a), [2]). In order to drive the main rotor, a Pratt \& Whitney PT6T-3 turboshaft engine with a maximum continuous rating of $1,600 \mathrm{shp}$ was used in the XH-59A pure helicopter. In addition, it recorded a maximum level flight speed of 160 knots. Afterward, two auxiliary propulsions were added to the XH-59A helicopter for the compound helicopter mode (Figure 1(b), [9]). Pratt \& Whitney J60-P-3A turbojet engines with a total static thrust of $6,600 \mathrm{lb}$ at sea level were used for high-speed flight. The designed rotor tip speed of the XH-59A pure helicopter configuration is $650 \mathrm{ft} / \mathrm{sec}$. However, the rotor tip speed must be reduced for high-speed flight above 160 knots in order to prevent the Mach number at the blade tip on the advancing side of the rotor from exceeding 0.85 at high speeds. Therefore, the rotor tip speed is designed to be reduced to $450 \mathrm{ft} / \mathrm{sec}$ during high-speed flight [10]. The $\mathrm{XH}-$ 59A compound helicopter using auxiliary propulsion reached a maximum level flight speed of 240 knots [3]. The general properties of the XH-59A lift-offset compound helicopter are shown in Table $1[3,8,10]$.

Although the XH-59A technical demonstrator solved the low-speed problem of conventional helicopters, it has not been put into practical use due to the serious vibration problem and the technical limitations associated with the reduction in the rotation speed of the rotor [2]. The $\mathrm{XH}$ 59A helicopter suffered from a serious vibration problem, especially at a high-speed, since it uses very stiff and rigid blades and does not have any vibration control system. The vibration characteristics of the XH-59A compound helicopter using auxiliary propulsion were investigated in a flight test with both cross-over angles of $90^{\circ}$ and $0^{\circ}$ [8]. The cross-over angle of a coaxial rotor is the azimuth angle at which the upper and lower rotor blades cross over each other, as defined in Figure 3 [11]. In Figure 3, the azimuth angle is based on
TABLE 1: General properties of XH-59A lift-offset compound helicopter.

\begin{tabular}{|c|c|}
\hline Hub type & Hingeless rotor \\
\hline Radius [ft] & 18 \\
\hline Number of rotors & 2 \\
\hline Number of blades & 3 \\
\hline Total solidity, $\sigma$ & 0.127 \\
\hline \multicolumn{2}{|l|}{ Tip speed $[\mathrm{ft} / \mathrm{sec}], V_{\text {tip }}$} \\
\hline Helicopter mode & 650 \\
\hline Compound helicopter mode & 450 \\
\hline \multicolumn{2}{|l|}{ Maximum speed [knots] } \\
\hline Helicopter mode & 160 \\
\hline Compound helicopter mode & 240 \\
\hline \multicolumn{2}{|l|}{ Horizontal tail } \\
\hline Area $\left[\mathrm{ft}^{2}\right]$ & 60 \\
\hline Span $[\mathrm{ft}]$ & 15.50 \\
\hline Tail length [ft] & 20.30 \\
\hline \multicolumn{2}{|l|}{ Vertical tail } \\
\hline Area $\left[\mathrm{ft}^{2}\right]$ & 30 \\
\hline Span $[\mathrm{ft}]$ & 12 \\
\hline Tail length [ft] & 20.30 \\
\hline \multicolumn{2}{|l|}{ Fuselage } \\
\hline Length [ft] & 40.5 \\
\hline Width [ft] & 6.08 \\
\hline Height $[\mathrm{ft}]$ & 6.08 \\
\hline Rotor separation [ft] & 2.5 \\
\hline \multicolumn{2}{|l|}{ Power plants } \\
\hline Lift & PT6T-3 turboshaft engine \\
\hline Thrust & J60-P-3A turbojet engine \\
\hline
\end{tabular}

the azimuth angle of the upper rotor rotating in the counterclockwise direction. From the flight test results of the $\mathrm{XH}$ 59A helicopter, the following vibration characteristics were confirmed. First, there is a difference in the characteristics of the $3 \mathrm{P}$ hub loads in terms of the cross-over angle. For example, the $3 \mathrm{P}$ pitch moment of the hub is more dominant than the $3 \mathrm{P}$ roll moment of the hub for a cross-over angle of $0^{\circ}$, but the characteristics of the hub vibratory loads are opposite for a cross-over angle of $90^{\circ}$ [8]. Second, the $2 \mathrm{P}$ component of the rotating blades caused mainly the $3 \mathrm{P}$ hub loads of the XH-59A helicopter [11, 12]. In addition, the 3P pitching or rolling moment greatly affects the vibration of the XH-59A aircraft [8].

For the present validation study, various test data and previous analysis results for the XH-59A helicopter are used, which can be found in $[4,8,13]$.

\section{Rotorcraft Analysis Tool: CAMRAD II}

CAMRAD II [5], developed by Johnson Aeronautics in the US, is a comprehensive analysis tool for rotorcrafts. CAMRAD II can conduct comprehensive analyses of the performance, the aerodynamic and structural loads, the aeroelasticity stability of rotorcrafts, and so on. CAMRAD 


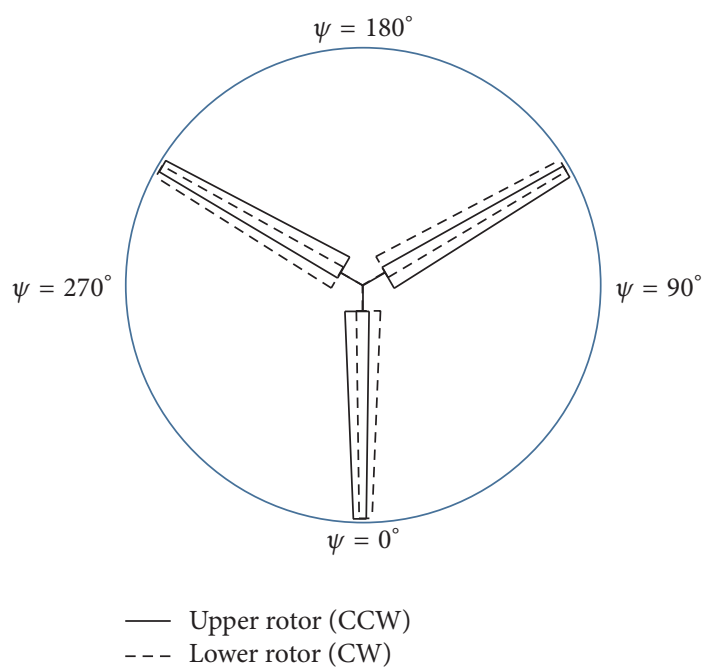

(a) Cross-over angle of $0^{\circ}$

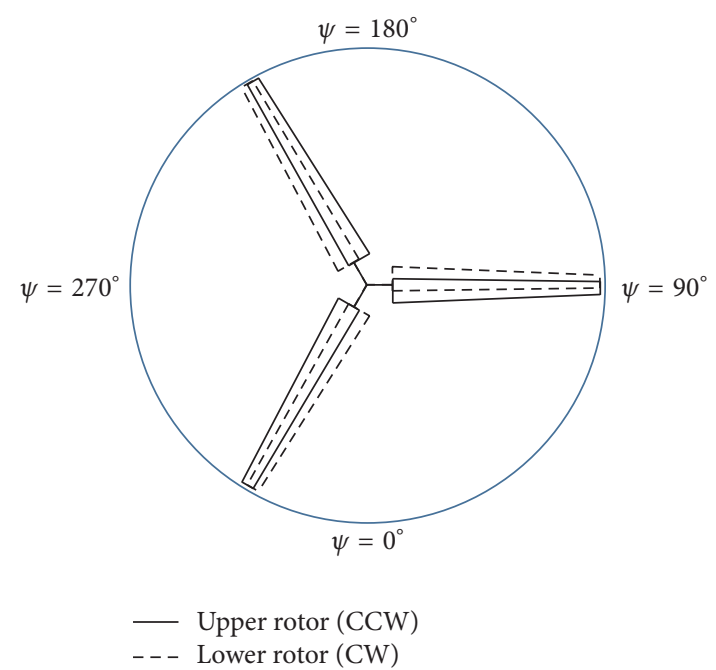

(b) Cross-over angle of $90^{\circ}$

FIgURE 3: Definition of cross-over angle of coaxial rotor (azimuth angle is based on the rotor rotating counter-clockwise direction).

II has nonlinear finite elements, multibody dynamics, and rotorcraft aerodynamics with various inflow and wake models [14]. Therefore, CAMRAD II has been widely used for rotorcraft research.

The CAMRAD II analysis is roughly divided into three parts: the trim, transient, and flutter tasks. In the trim task, the equilibrium solution is calculated for steady-state flight conditions. In the transient task, the equations from the trim task are numerically integrated for a prescribed excitation. The flutter task solves differential equations linearized for the trim task [5].

The aerodynamic forces acting on the rotor blades are calculated using lifting-line theory considering an unsteady flow, compressibility, and viscosity and the rotor wake model [14]. The wake models used in CAMRAD II include the prescribed wake, rolled-up wake, multiple-trailer wake, and multiple-trailer with consolidation wake [5].

The rotor blades can be modeled as finite elements of nonlinear elastic beam components. CAMRAD II can consider anisotropic or composite materials as well as isotropic materials for structural modeling of the blade. There are three beam geometry models: the exact model, the almost-exact model, and the second-order approximation model [15]. In addition, each finite element for the nonlinear elastic beams has a total of 15 degrees of freedom ( 6 rigid body motions and 9 elastic motions, [5]).

The trim of the rotorcraft is calculated using the Newton Raphson method with a Jacobian matrix. The thrust, rolling moment, and pitching moment are the trim targets. In addition, the trim analysis is usually conducted at a low azimuthal resolution of $15^{\circ}$ [16].

CAMRAD II can conduct a comprehensive analysis for not only conventional helicopters but also helicopters with various configurations, such as a tandem helicopter, tiltrotor, and coaxial lift-offset compound helicopter. However, it is difficult to establish techniques for modeling and analysis using CAMRAD II, since numerous input variables and empirical parameters are required.

\section{Analysis Techniques}

4.1. CAMRAD II Modeling Techniques. In this section, the modeling and analysis techniques for CAMRAD II are discussed. As mentioned in previously, a flight test of the $\mathrm{XH}$ 59A lift-offset compound helicopter was conducted using two cross-over angle configurations of $90^{\circ}$ and $0^{\circ}$. However, the present CAMRAD II model uses only the cross-over angle of $0^{\circ}$, as shown in Figure 4.

Figure 5 presents the blade thickness and airfoil distribution. Similar to the method used in [4, 7], airfoils similar to the actual airfoil characteristics of the XH-59A helicopter are used for the present analysis model, since actual airfoil data for the XH-59A helicopter are not given in the public domain. Furthermore, similar to the way used in $[4,17]$, the drag increment is appropriately applied to obtain better correlation results for performance analysis, because the C81 airfoil tables used in this study does not exactly represent the characteristics of the actual $\mathrm{XH}-59 \mathrm{~A}$ rotor aerodynamics including Reynolds number. This study uses the assumed C81 airfoil tables generated at relatively low Reynolds number, and their mean drag values are estimated to be higher than the actual airfoil data for the XH-59A rotor. Therefore, the decrease (negative increment) of drag coefficients is applied for the C81 airfoil tables used for the present analyses in order to obtain almost the same power as the flight test data. Then, the performance correlation and vibration analyses in forward flight condition are conducted using the adjusted drag coefficients.

The blades are modeled as 16 aerodynamic panels, and the width of a panel is 7\% $R$ at the root and 3\% $R$ at the tip, as shown in Figure 6. The general free wake model is used for all of the present analyses. In addition, the wake 


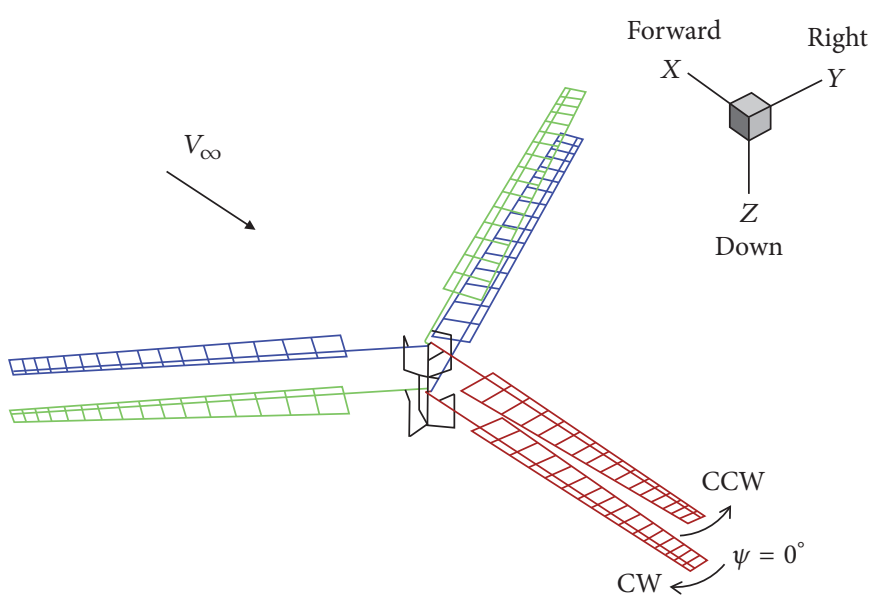

FIGURE 4: CAMRAD II model of XH-59A rotor.

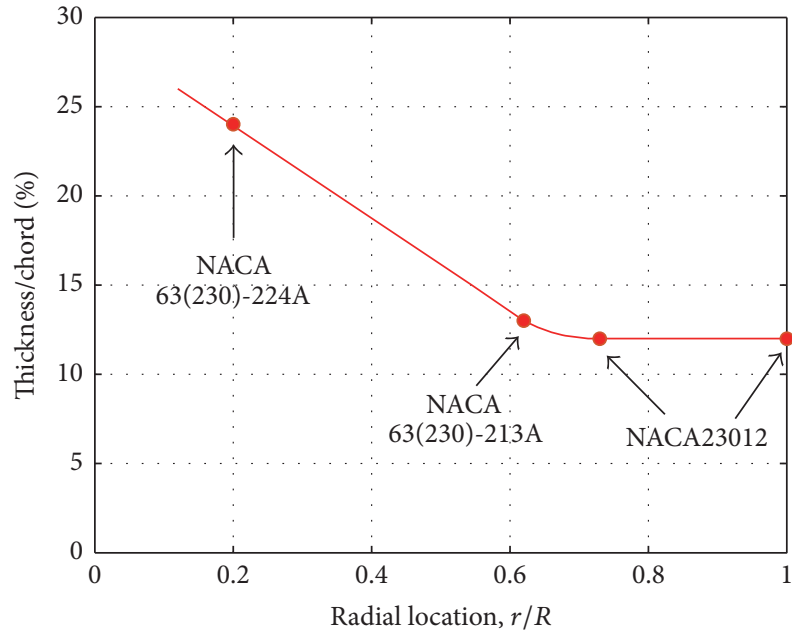

(a) Actual airfoils

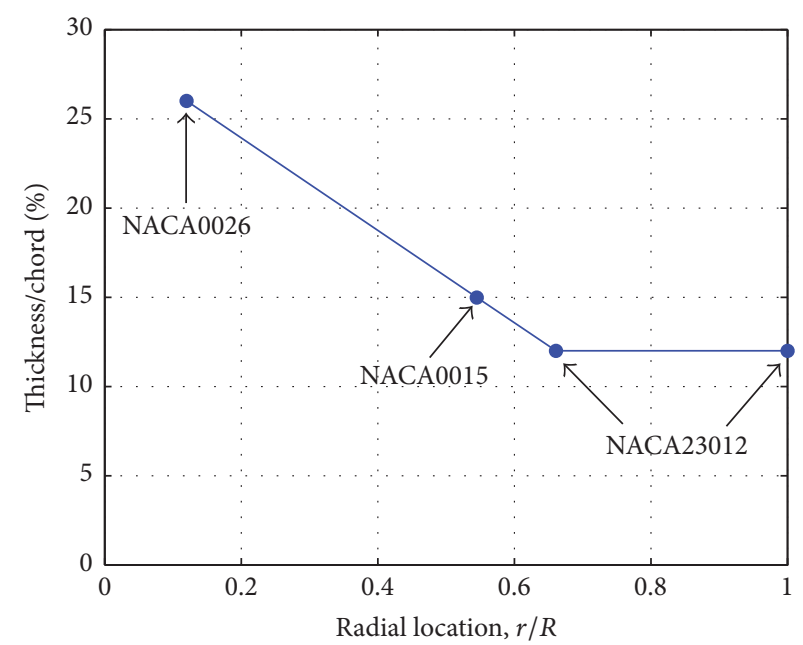

(b) Present airfoil model

FIGURE 5: Blade thickness and airfoil distribution.

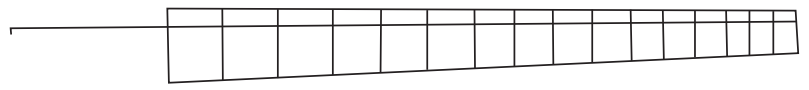

FIgURE 6: Aerodynamic panel model.

interaction between the upper and lower rotors is considered. The model of the vortex core size in the free wake model is very important to obtain a good prediction. The initial core size in the free wake model is generally $10-20 \% c$ at the blade tip. However, the present CAMRAD II analysis uses an initial core size of $50 \% c$ at the blade tip [4] in order to obtain better correlation results with the flight test. In addition, the vortex core grows with the square root of the wake age by a square root model, as expressed in (2). Equation (2) considers that the scaling factor $k$ determines how quickly the vortex core grows [17].

$$
\frac{r_{c}}{c}=\frac{r_{c 0}}{c}+\sqrt{\frac{\zeta}{2 \pi k}}
$$

Figure 7 shows the finite element model of a XH-59A rotor blade. Each rotor blade of the XH-59A is modeled as a nonlinear elastic beam with seven finite elements. It is not required generally that the number of aerodynamic panels should be the same as the number of finite beam elements for the modeling of rotor aeromechanics analyses. The crosssectional beam properties, which are summarized in Table 2 , are obtained from [18] and slightly modified to match the nonrotating blade frequencies. The pitch hinge of the $\mathrm{XH}-$ $59 \mathrm{~A}$ hingeless rotor is located at $5 \% R$. In addition, a rotor control system including the pitch link, swashplates, and pitch horn is considered as well as the rotor blades. The stiffness of the control system is modeled in the present CAMRAD II model, and the pitch-link stiffness is appropriately determined in order to match the nonrotating frequency in the first torsion mode (T1).

4.2. Trim Analyses. A trim analysis for forward flight is conducted such that the three force and three moment components acting on the aircraft are zero. For the vehicle 


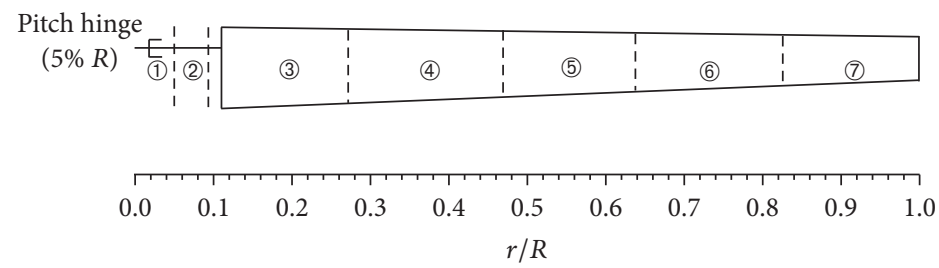

FIGURE 7: Finite element model.

TABLE 2: Blade cross-sectional beam properties.

\begin{tabular}{|c|c|c|c|c|c|}
\hline \multirow{2}{*}{$\begin{array}{l}\text { Radial station } \\
r / R\end{array}$} & \multicolumn{2}{|c|}{ Bending stiffness [lb- $\left.\mathrm{ft}^{2}\right]$} & \multirow{2}{*}{$\begin{array}{c}\text { Torsion stiffness }\left[\mathrm{lb}-\mathrm{ft}^{2}\right] \\
G J\end{array}$} & \multirow{2}{*}{$\begin{array}{l}\text { Section mass }[\mathrm{slug} / \mathrm{ft}] \\
m\end{array}$} & \multirow{2}{*}{$\begin{array}{l}\text { Mass moment of inertia [slug-ft] } \\
\qquad I_{\theta}\end{array}$} \\
\hline & $E I_{\text {Flap }}$ & $E I_{\text {Lag }}$ & & & \\
\hline 0.0000 & 5972000 & 5972200 & 4784700 & 3.6178 & 0.0453 \\
\hline 0.0920 & 5972000 & 5972200 & 4784700 & 3.6178 & 0.0453 \\
\hline 0.0921 & 5972000 & 5972200 & 4784700 & 0.8205 & 0.0453 \\
\hline 0.1150 & 4220000 & 4375000 & 4210000 & 0.6713 & 0.0453 \\
\hline 0.1151 & 4220000 & 4375000 & 4210000 & 0.6713 & 0.0381 \\
\hline 0.1390 & 3540000 & 3860000 & 3500000 & 0.6120 & 0.0381 \\
\hline 0.1391 & 3540000 & 3860000 & 3500000 & 0.6120 & 0.0321 \\
\hline 0.1620 & 2880000 & 3400000 & 2860000 & 0.5520 & 0.0321 \\
\hline 0.1621 & 2880000 & 3400000 & 2860000 & 0.5520 & 0.0365 \\
\hline 0.2300 & 1670000 & 2740000 & 1528000 & 0.4380 & 0.0350 \\
\hline 0.3000 & 1080000 & 2230000 & 1040000 & 0.3432 & 0.0291 \\
\hline 0.4000 & 680000 & 1770000 & 540000 & 0.2532 & 0.0202 \\
\hline 0.5000 & 410000 & 1500000 & 260000 & 0.2016 & 0.0161 \\
\hline 0.6000 & 240000 & 1250000 & 110000 & 0.1488 & 0.0117 \\
\hline 0.7000 & 150000 & 980000 & 60000 & 0.1152 & 0.0096 \\
\hline 0.7370 & 140000 & 880000 & 50000 & 0.1044 & 0.0090 \\
\hline 0.7371 & 140000 & 880000 & 50000 & 0.1566 & 0.0090 \\
\hline 0.8000 & 110000 & 730000 & 40000 & 0.1452 & 0.0077 \\
\hline 0.9000 & 90000 & 500000 & 22000 & 0.1268 & 0.0055 \\
\hline 0.9390 & 80000 & 460000 & 21000 & 0.1194 & 0.0047 \\
\hline 0.9391 & 80000 & 460000 & 21000 & 0.3804 & 0.0047 \\
\hline 0.9730 & 70000 & 420000 & 20900 & 0.3804 & 0.0042 \\
\hline 0.9731 & 70000 & 420000 & 20900 & 0.4625 & 0.0042 \\
\hline 1.0000 & 55600 & 388900 & 20800 & 0.4625 & 0.0042 \\
\hline
\end{tabular}

trim, the aerodynamic coefficients for the XH-59A fuselage are obtained from [13]. The mean collective pitch angle, the lateral and longitudinal cyclic pitch angles of each rotor, and the pitch and roll angles of the aircraft are used as the trim variables of the lift-offset rotorcraft. In addition, the primary controls of the rotor are calculated from the pilot control inputs mixed with the control phase angle. The control phase refers to the combination of the lateral and longitudinal cyclic pitches for controlling the lift-offset rotor [4]. Because the azimuth angle at which the cyclic pitch should be applied to generate a particular moment is different from the input azimuth angle for the articulated rotors, a shift in the azimuth occurs. The control phase angle of the ABC rotor is generally $30^{\circ}-40^{\circ}$ since the rotor blade has a high stiffness, whereas the phase angle is approximately $80^{\circ}-90^{\circ}$ for articulated rotor systems [8].
Alternatively, the trim can also be determined by considering the six primary rotor controls of the upper and lower rotors when the pitch angle of the aircraft is fixed at approximately $0^{\circ}$, which provides the best performance for the lift-offset rotor [8]. The trim targets can be set as the vertical force equivalent to the weight of the fuselage, the torque offset of the upper and lower rotors, and the pitching and rolling moments of the upper and lower rotors. The liftoffset can be considered as the differential rolling moment.

4.3. Performance and Vibration Analyses. The performance of the XH-59A helicopter is evaluated using (3)-(6). In the CAMRAD II analysis, the rotor power of each of the upper and lower rotors is defined as

$$
P=P_{i}+P_{o}+P_{p} .
$$


In addition, the lift-to-drag ratio of the aircraft, $L / D$, and the effective lift-to-drag ratio of the rotor, $L / D_{e}$, are, respectively, defined as

$$
\begin{aligned}
\frac{L}{D} & =\frac{W V}{P_{\text {coaxial }}} \\
\frac{L}{D_{e}} & =\frac{L}{\left(P_{\text {coaxial }} / V+X\right)},
\end{aligned}
$$

where the rotor power $P_{\text {coaxial }}$ is the sum of each power of the upper and lower rotors:

$$
P_{\text {coaxial }}=P_{\text {upper }}+P_{\text {lower }},
$$

where $P_{\text {upper }}$ and $P_{\text {lower }}$ are calculated using (3).

For the vibration analysis of the XH-59A helicopter, the 3P hub moments are calculated using

$$
M_{3 \mathrm{P}}=\sqrt{\left[M_{3 \mathrm{Pc}}^{\text {upper }}+M_{3 \mathrm{Pc}}^{\text {lower }}\right]^{2}+\left[M_{3 \mathrm{Ps}}^{\text {upper }}+M_{3 \mathrm{Ps}}^{\text {lower }}\right]^{2}},
$$

where the superscripts upper and lower represent the upper and lower rotors, respectively, and the subscripts $\mathrm{c}$ and $\mathrm{s}$ indicate the cosine and sine components of the hub loads, respectively [7].

Figure 8 shows the results of a fan plot analysis using CAMRAD II with the discussed modeling techniques for validating the rotor structural dynamics model. The present first torsional frequency (T1) in the nonrotating condition is well correlated with the test data [13], as compared to the results of previous analyses $[8,13]$. Therefore, it can be considered that the rotor structural dynamics model in the present CAMRAD II analysis is successfully verified.

\section{Analysis Results}

5.1. Performance Analyses for Pure Helicopter Configuration. In this study, performance analyses using CAMRAD II are conducted for the $\mathrm{XH}-59 \mathrm{~A}$ helicopter in various flight conditions, and the results of the performance analyses are compared with flight test data and previous analyses [4].

Figure 9 shows the figure of merit in terms of the thrust for the XH-59A pure helicopter mode without auxiliary propulsion in hover. The result of the present analysis is compared well with the flight test data and previous analysis result [4]. In particular, the figure of merit of the XH-59A rotor, which appears between 0.75 and 0.8 , is better than the typical figure of merit of $0.6-0.75$ for conventional helicopter rotors [19]. This good hover performance results from the fact that the wake of the upper rotor is contracted before reaching the lower rotor in the case of a coaxial rotor [4].

Figure 10 presents the rotor power in terms of the flight speed in forward flight for the XH-59A helicopter without auxiliary propulsion. As shown in Figure 10, the result of the present analysis is validated well with the flight test data [4] and the previous CAMRAD II analysis using the prescribed wake model [4]. In addition, it is considered that the result of the present analysis around 160 knots is better agreement with the flight test result [4] than the previous analysis [4].

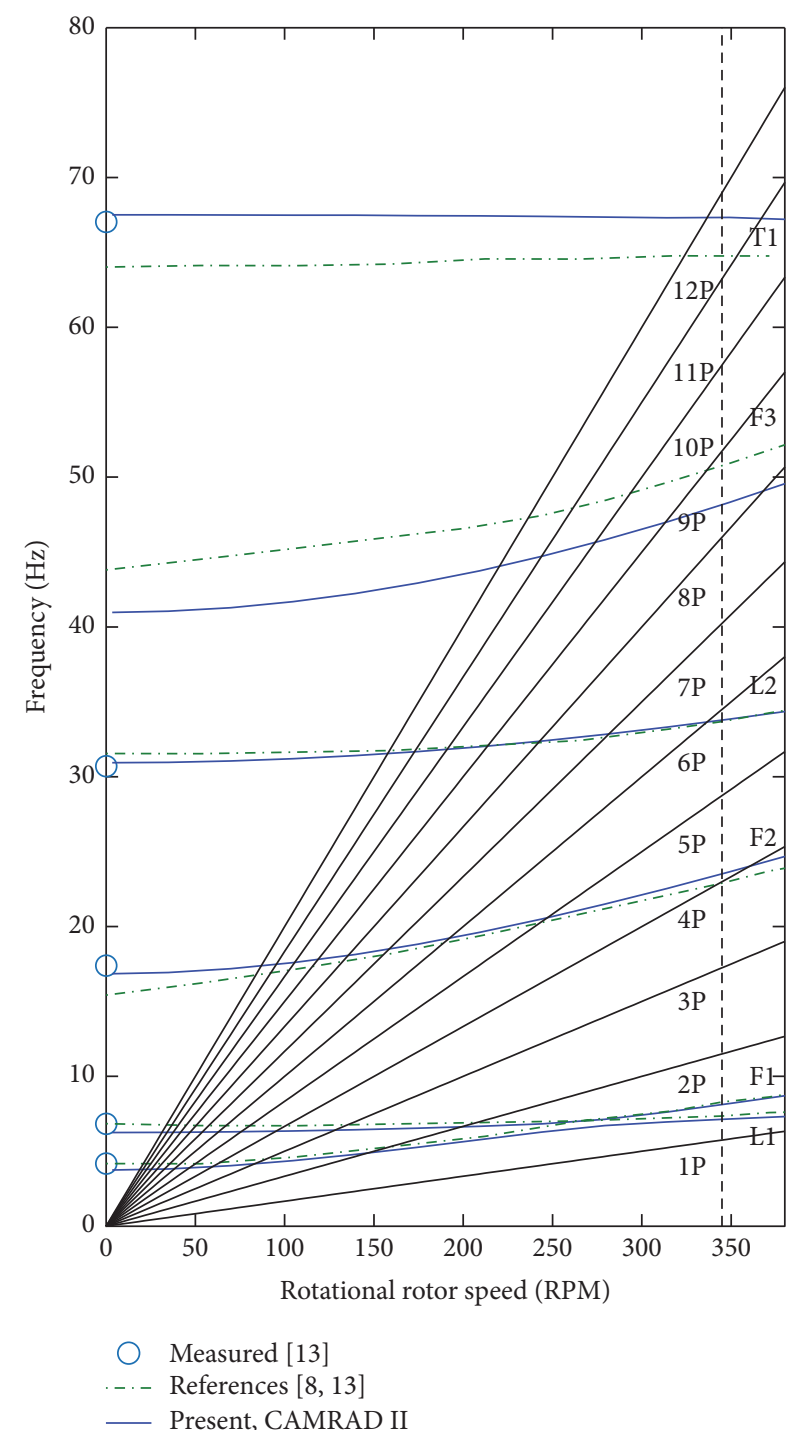

FIGURE 8: Validation of the natural frequency (L: lead-lag mode, F: flap mode, T: torsional mode, and P: per revolution).

Figure 11 shows the result for the lift-to-drag ratio of the aircraft in the pure helicopter mode without auxiliary propulsion in forward flight. Although the present analysis tends to be slightly overpredicted compared to the flight test result at 100-160 knots, the present analysis is correlated well with both the flight test data [4] and the result of the previous analysis using the prescribed wake model [4].

\subsection{Performance Analyses for Compound Helicopter Configu-} ration. Figure 12 shows the effective lift-to-drag ratio of the rotor for the XH-59A compound helicopter configuration in forward flight. All of the flight test data in Figure 12 are for the compound helicopter mode with a gross weight ranging from 11,000 to $13,000 \mathrm{lb}$. However, the gross weight of the $13,000 \mathrm{lb}$ model is used for the present CAMRAD II analysis. In addition, the present analysis uses the lift-offset values of $0.1-0.3$. The results of the present analyses using lift-offset values of 0.2 and 0.3 are correlated well with the flight test 


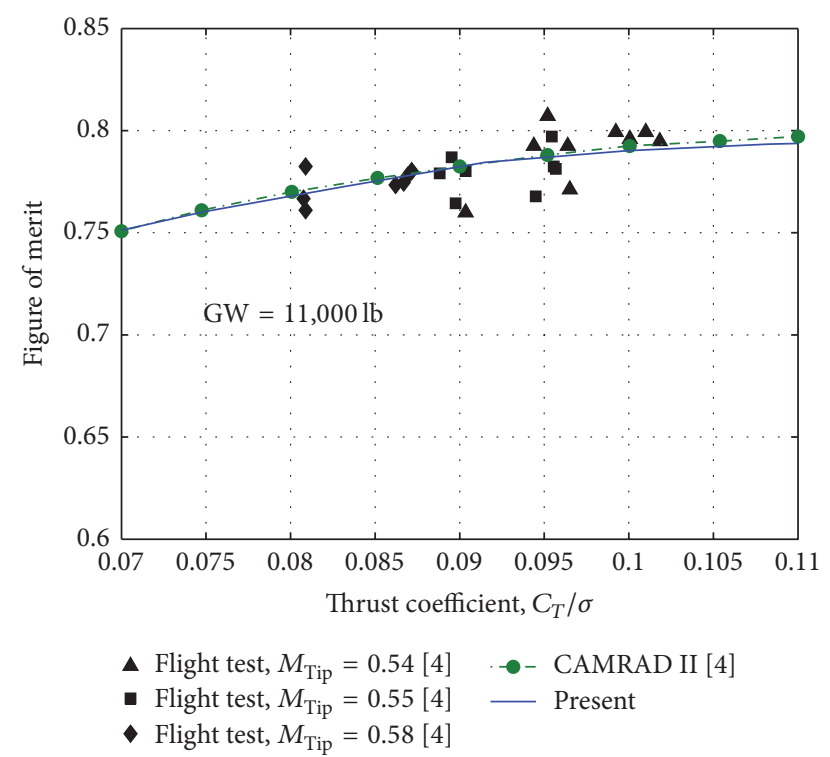

FIGURE 9: Figure of merit.

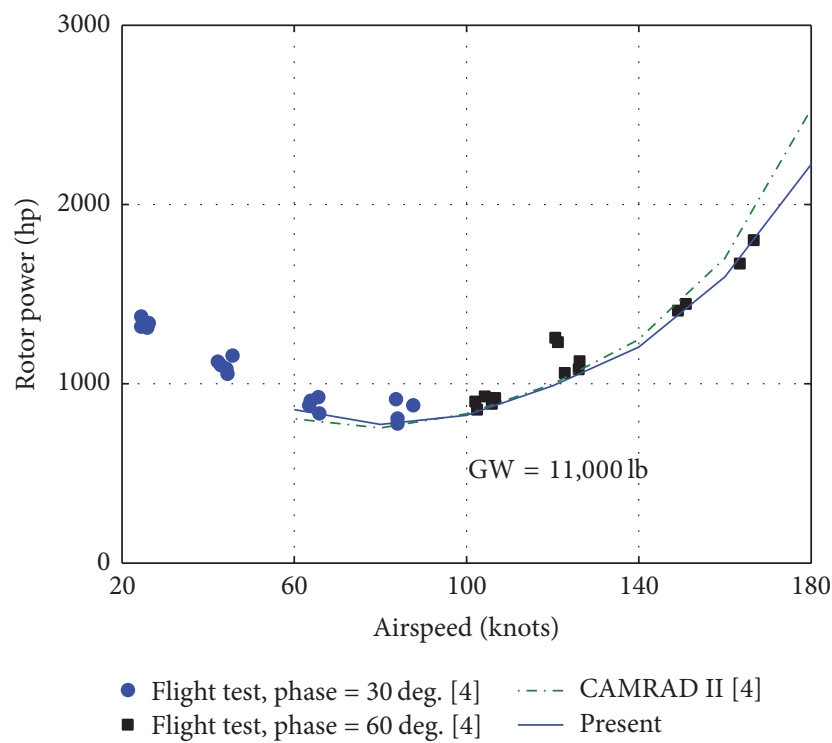

FIGURE 10: Validation of rotor power in pure helicopter mode.

data [4] since the present results exist between the upper and lower bounds of the flight test data. In addition, for the liftoffset values of 0.2 and 0.3 , the results of the present analyses with the general free wake model compare well with those of a previous analysis using the prescribed wake model [4], especially in high-speed flight. Therefore, the technique for the performance analysis using CAMRAD II with the general free wake model is well established through the validation results given in Figures 9-12.

5.3. Vibration and Structural Loads Analyses. The 3P hub loads and the structural loads of the blade are analyzed using CAMRAD II for the XH-59A compound helicopter configuration with auxiliary propulsion in forward flight. As

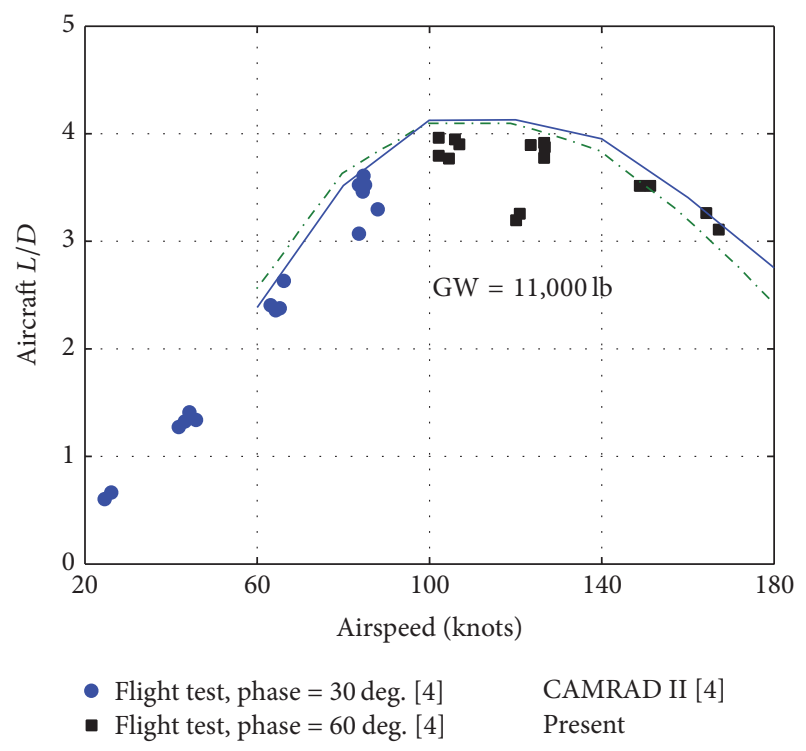

FIGURE 11: Validation of aircraft lift-to-drag ratio in pure helicopter mode.

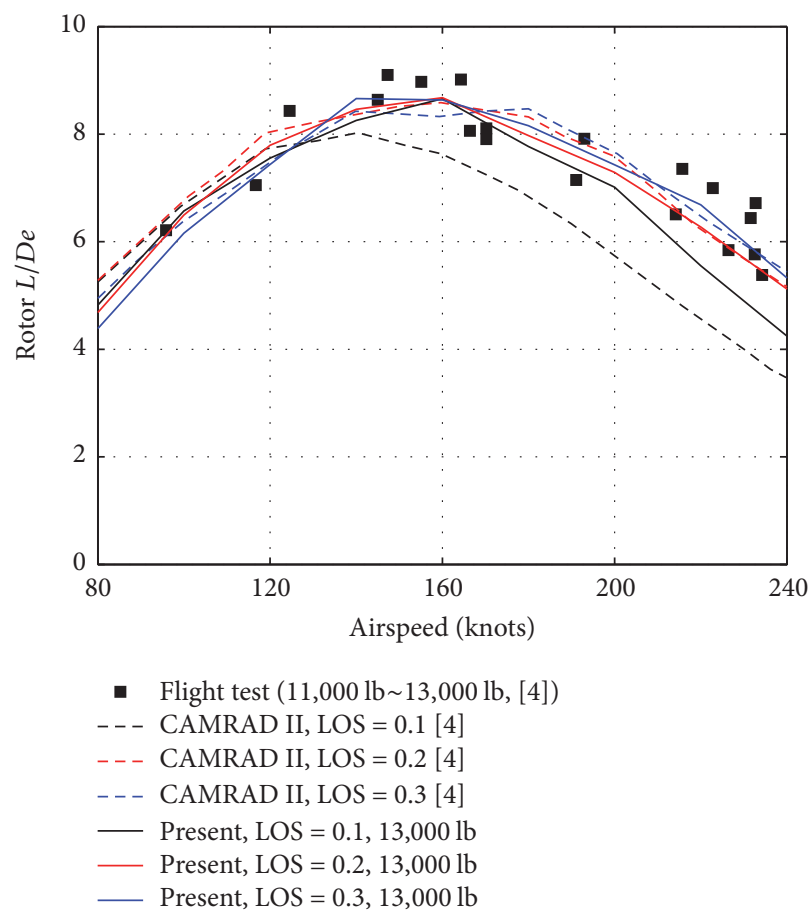

FIGURE 12: Validation of the rotor effective lift-to-drag ratio in compound helicopter mode.

described in Section 4, the model with a cross-over angle of $0^{\circ}$ is used for the present analysis.

Figure 13 shows the $3 \mathrm{P}$ vibratory loads of the hub in terms of the forward flight speed because the $3 \mathrm{P}$ component of the hub vibratory loads is the most dominant. As shown in Figure 13, the 3P hub moments increase as the flight speed increases. The 3P hub pitching moment is much higher than the $3 \mathrm{P}$ hub rolling moment when a cross-over angle of $0^{\circ}$ is used for the $\mathrm{XH}-59 \mathrm{~A}$ helicopter. Although there are only 


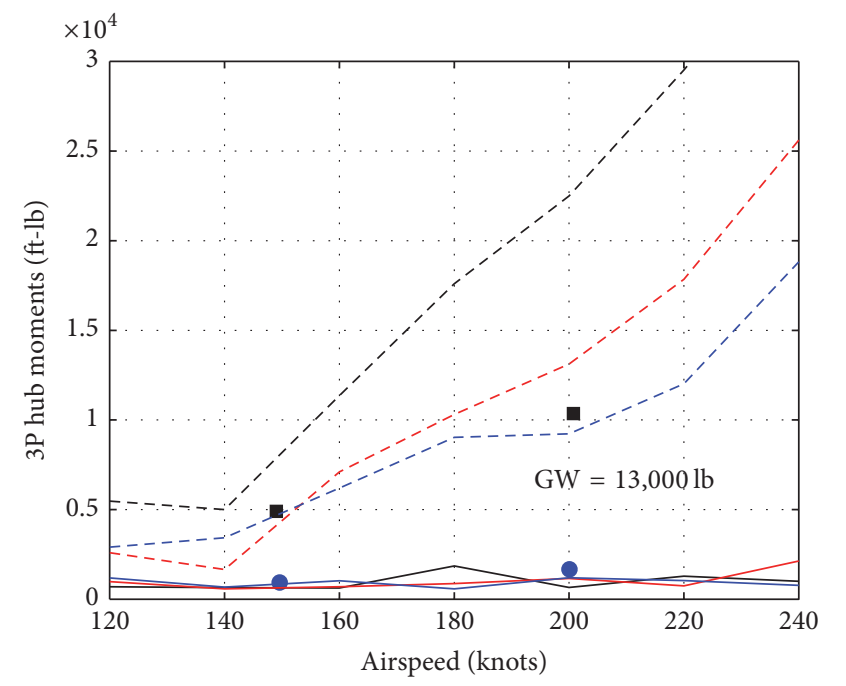

Plight test, roll moment [8]
$\quad$ Flight test, pitch moment $[8]$
$-\quad$ Present, roll moment, LOS $=0.1$
$-\quad$ Present, roll moment, LOS $=0.2$
$-\quad$ Present, roll moment, LOS $=0.3$
$---\quad$ Present, pitch moment, LOS $=0.1$
$---\quad$ Present, pitch moment, LOS $=0.2$
$---\quad$ Present, pitch moment, LOS $=0.3$

FIGURE 13: Validation of 3P hub moments in compound helicopter mode.

two test data points for the $3 \mathrm{P}$ hub moments in the Figure 13, the present analysis using a lift-offset of 0.3 is correlated well with the flight test data [8]. Therefore, the vibration analysis technique for the XH-59A lift-offset compound helicopter is also appropriately established.

Figure 14 shows the $2 \mathrm{P}$ flap bending moments of the rotating blades at $10 \% R$ for each of the upper and lower rotors. It is known that the $2 \mathrm{P}$ component of the rotating blades seriously affects the $3 \mathrm{P}$ hub loads $[11,12]$. Thus, the $2 \mathrm{P}$ components of the flap bending moments of the blade at $10 \% R$ for the upper and lower rotors are investigated using the lift-offset value of 0.3 . However, this result is not correlated with the flight test data since there is no flight test result for the $2 \mathrm{P}$ flap bending moment of the $\mathrm{XH}$ 59A compound helicopter. As seen in Figure 14, the 2P flap bending moments of the blade for both the upper and lower rotors significantly increase as the flight speed increases. Therefore, it is verified that the $2 \mathrm{P}$ flap bending moments affect the 3P hub loads since the trends in Figures 13 and 14 are similar to each other.

Figure 15 shows the analysis results of the structural loads of the blade for each of the upper and lower rotors. Because the flap bending moment at the blade root is particularly important, the $1 / 2$ peak-to-peak values of the flap bending moments of the blade at $10 \% R$ are investigated. The present analysis considers the lift-offset value of 0.3 since this value allows a good prediction for the $3 \mathrm{P}$ hub moments, as previously discussed in Figure 13. As shown in Figure 15, the present results for both the upper and lower rotors are significantly overpredicted compared to flight test results.

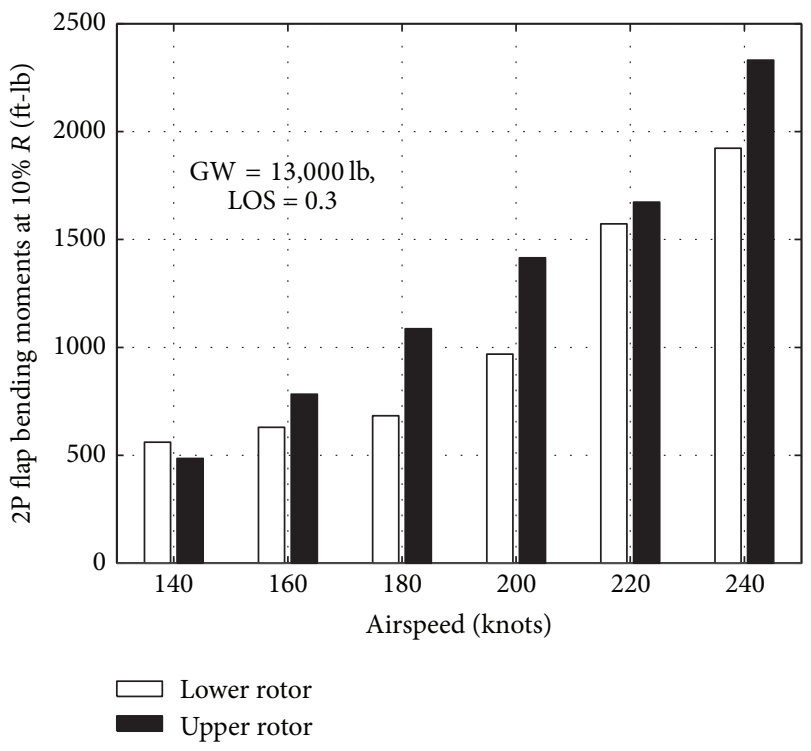

Figure 14: $2 \mathrm{P}$ flap bending moments at $10 \% R$ in compound helicopter mode.

The present prediction results for the upper and lower rotors are quite similar to each other. However, the trend of the analysis results is moderately different from the flight test data because the present results for both the upper and lower rotors are almost constant up to 220 knots, and they increase after 220 knots. It is considered that the difference in the results of the present analysis and flight test is due to the following reasons. First, the aircraft trim condition in the present analysis differs from that in the flight test condition. The lift-offset value of the present analysis is fixed as a given value of the entire flight speed range; however, the lift-offset value of the flight test varies with the control phase angle as the flight speed increases. Second, it is generally difficult to predict the structural moments of the blade precisely using the rotorcraft comprehensive analysis. Therefore, it is necessary to improve the analysis technique for the structural loads of the blade for the lift-offset compound helicopters.

5.4. Airloads Analyses. The airloads on the blades of the XH59A helicopter were not measured during flight tests, but in this study, an airloads analysis of the XH-59A helicopter with lift-offset value of 0.3 is conducted. Figure 16 shows lift distributions of the rotor disks at 140 knots. As shown in Figure 12, the XH-59A helicopter shows the best performance of the effective lift-to-drag ratio of the rotor at a flight speed of approximately 140 knots. In Figure 16, the following aerodynamic characteristics of the XH-59A rotor can be observed. First, the most lift is generated on each advancing side of the upper and lower rotors, which is a unique characteristic of the lift-offset helicopter, as previously described. Second, the lift distributions of the upper and lower rotors are quite similar to each other.

Figures 17 and 18 present the section lifts of the blade for both the upper and lower rotors at 140 and 240 knots, respectively, for the XH-59A compound helicopter with the lift-offset value of 0.3 . The section lifts of the blade are 


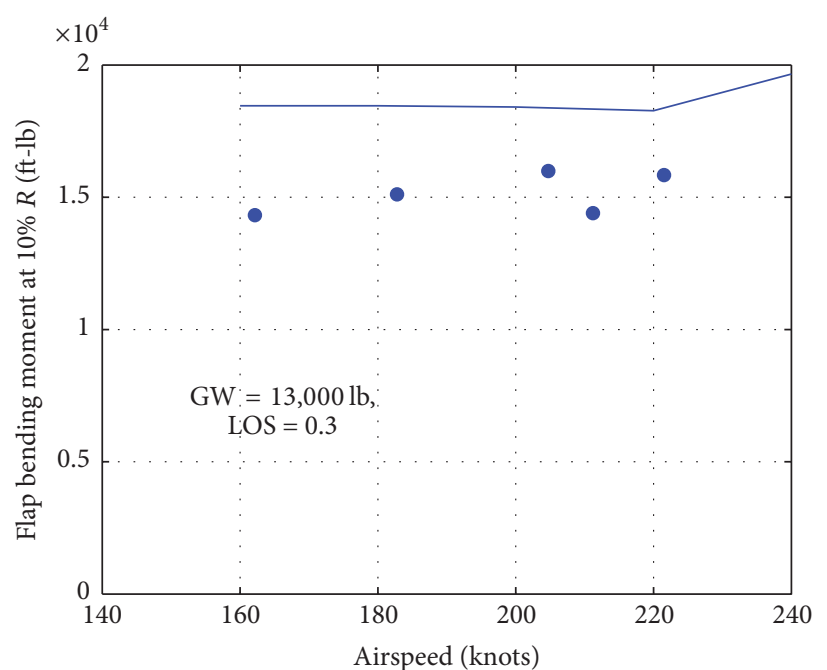

- Flight test [8] Present

(a) Lower rotor

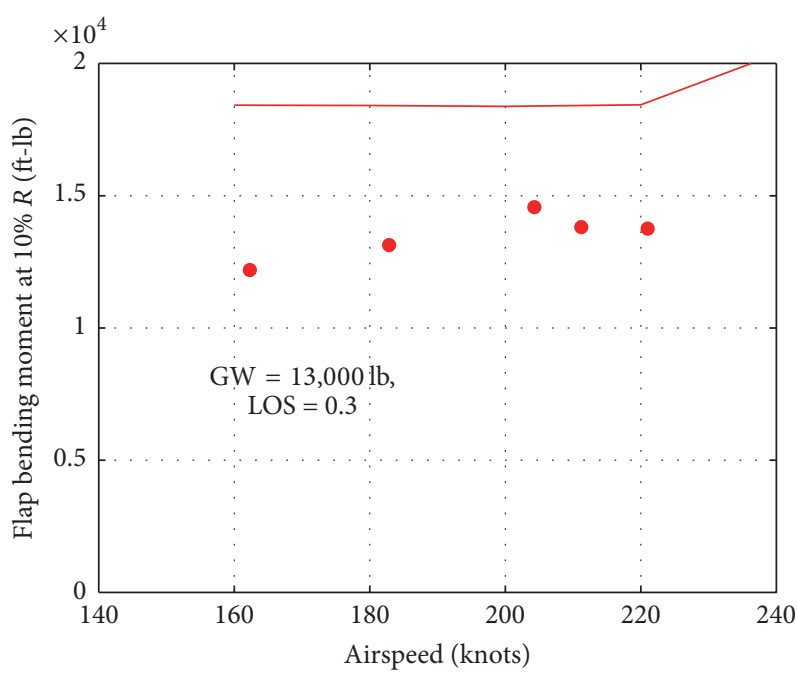

- Flight test [8] Present

(b) Upper rotor

FIGURE 15: Validation of blade structural loads at $10 \% R$ (1/2 peak-to-peak values, compound helicopter mode).

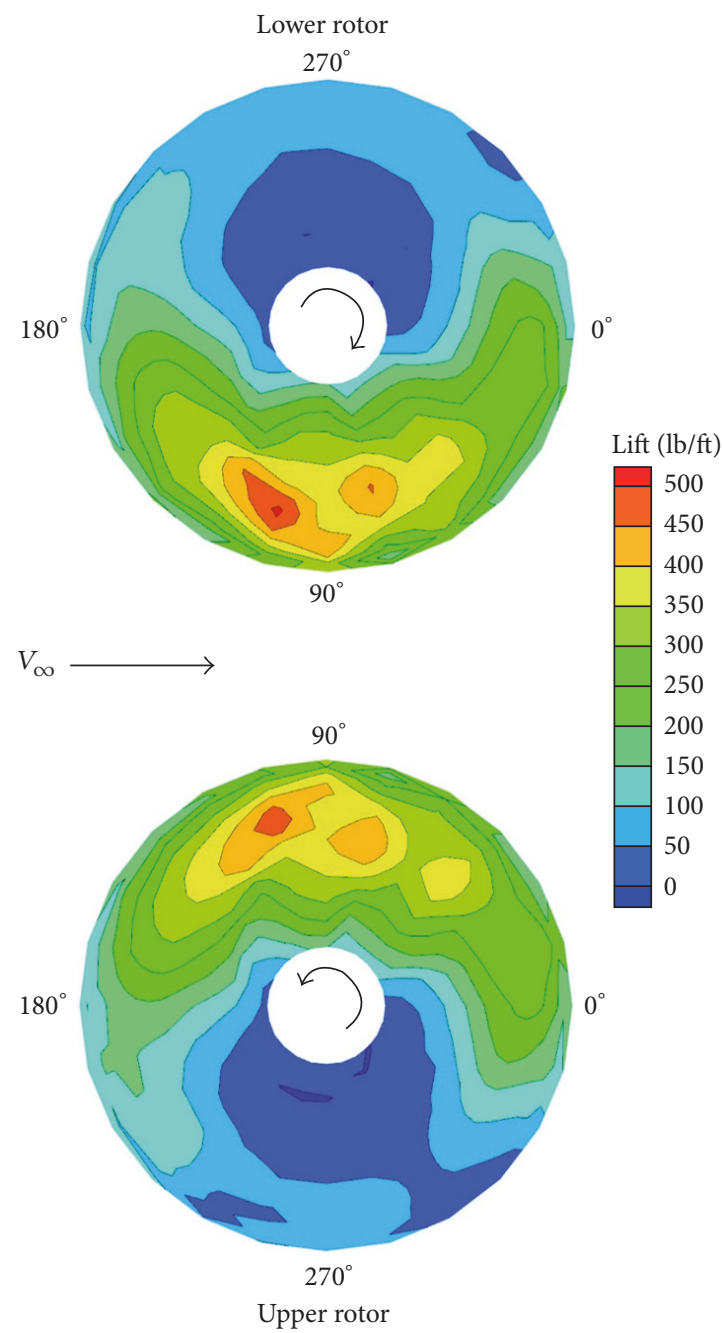

FIGURE 16: Lift distributions at 140 knots in compound helicopter mode (LOS $=0.3$ ). 

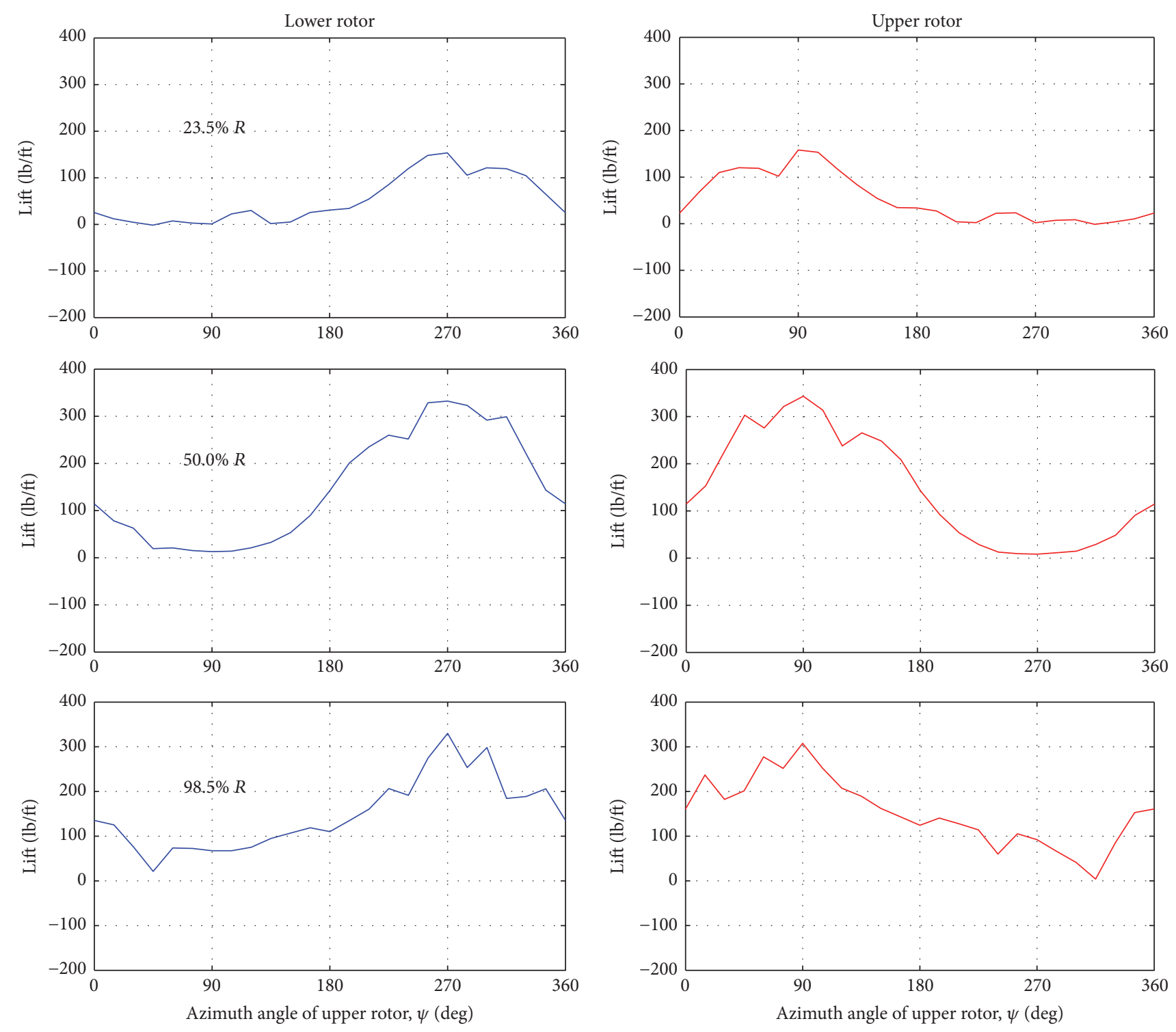

FIGURE 17: Blade section lifts at 140 knots in compound helicopter mode (LOS $=0.3$ ).

investigated at $23.5 \% R, 50.0 \% R$, and $98.5 \% R$ for the upper and lower rotor blades. In Figures 17 and 18, the azimuth angles are defined based on counter-clockwise rotation for the upper rotor. That is, the advancing side of the lower rotor is $360^{\circ}-180^{\circ}$ in the horizontal axis in the figure. The present results show that the variations and magnitudes of the section lifts of the upper and lower rotors are almost similar to each other at each blade section. The present analysis shows fluctuations in the lifts of both the upper and lower rotors for the blade outboard at 140 knots and for the blade midboard and outboard at 240 knots. It is considered that these fluctuations are caused by the interaction between the blades and the wake. In addition, the magnitude of the lift fluctuation for the lower rotor is larger than that of the upper rotor, especially for the results for the blade outboard at 140 knots and for the blade midboard at 240 knots since the lower rotor may be affected by the wake of the upper rotor. Particularly, the lifts at $98.5 \% R$ for both the upper and lower rotors at 240 knots definitely show negative tip loading phenomena in the first quadrants on the rotor disks. This is not observed in the analysis results at 140 knots. Further investigation for the airloads of a XH-59A rotor will be available with help of CFD (Computational Fluid Dynamics) analyses.

\section{Conclusions}

In this study, validation works of the performance and vibration analyses of the XH-59A lift-offset compound helicopter were conducted using CAMRAD II. The general free wake model, which is the most advanced wake model, was used in order to obtain accurate analysis results. The performance results obtained in this study for the XH-59A helicopter with and without auxiliary propulsion were in good agreement 

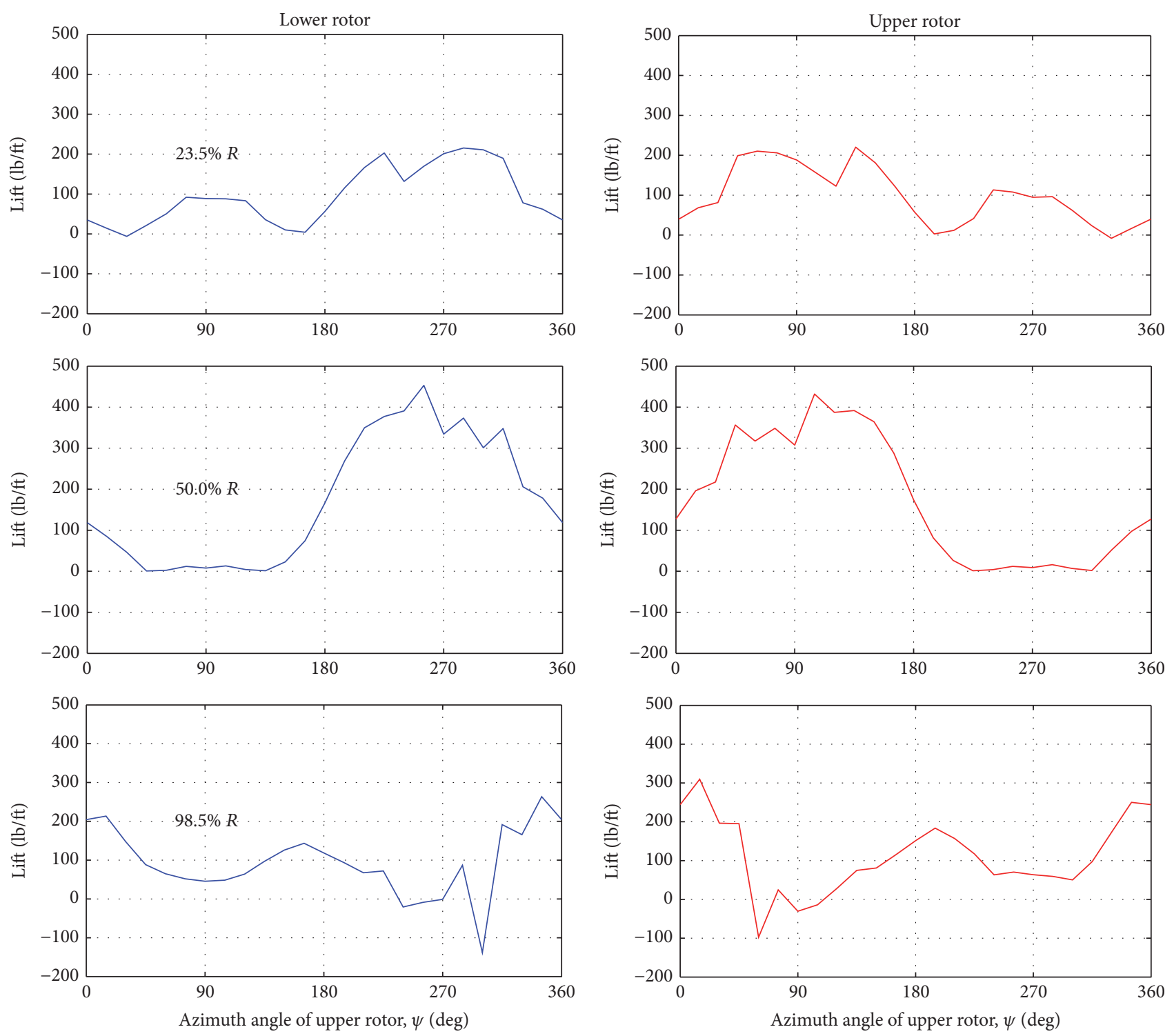

FIGURE 18: Blade section lifts at 240 knots in compound helicopter mode (LOS $=0.3$ ).

with the flight test data and previous analyses in both hover and forward flight conditions.

The hub vibratory loads and the structural loads of the blade for the $\mathrm{XH}-59 \mathrm{~A}$ helicopter with auxiliary propulsion were also investigated. For the $3 \mathrm{P}$ hub moments, the present CAMRAD II analysis with a lift-offset value of 0.3 was well correlated with the flight test data. However, the present analyses using a lift-offset value of 0.3 for the $1 / 2$ peakto-peak flap bending moments were not as good as the predictions for the $3 \mathrm{P}$ hub vibratory loads. Therefore, the technique for the analysis of the structural loads of the blade must be improved for lift-offset rotorcrafts.

Although the results of the present airloads analysis were not correlated with the flight test data of the XH-59A helicopter, the lifts for the XH-59A compound helicopter using the lift-offset value of 0.3 were calculated for the forward flight condition. The predicted lift distributions on the rotor disks showed that most of the lift is produced on the advancing side of each rotor disk, which is a unique characteristic of the lift-offset rotor.

Through the present validation study of a comprehensive analysis of the XH-59A compound helicopter, the techniques for the performance and vibration analyses of the compound helicopter using the lift-offset rotor were appropriately established. The established techniques for a comprehensive analysis of the XH-59A helicopter through this work will be used for the development of advanced compound rotorcrafts using lift-offset rotors.

\section{Nomenclature}

c: $\quad$ Blade chord length, $\mathrm{ft}$

$C_{T}$ : Thrust coefficient

$C_{T} / \sigma$ : Thrust coefficient divided by the solidity 


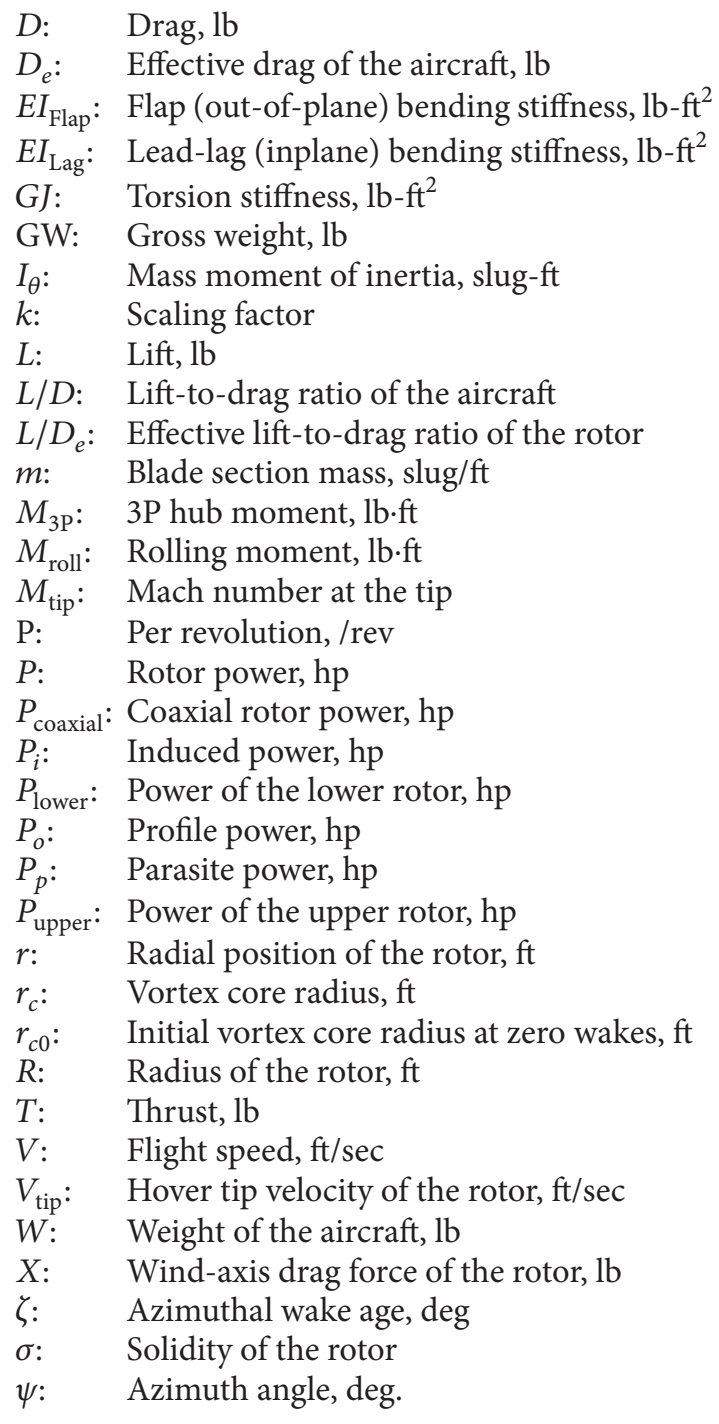

\section{Conflicts of Interest}

The authors declare that there are no conflicts of interest regarding the publication of this paper.

\section{Acknowledgments}

This research was supported by Basic Science Research Program through the National Research Foundation of Korea (NRF) funded by the Ministry of Science, ICT and Future Planning (NRF-2016R1C1B1007199). This work was supported by research fund of Chungnam National University. This work was supported by research fund of Korea Aerospace Research Institute. This work was conducted at High-Speed Compound Unmanned Rotorcraft (HCUR) research laboratory with the support of Agency for Defense Development (ADD).

\section{References}

[1] A. J. Ruddell, "Advancing blade concept $\left(\mathrm{ABC}^{\mathrm{TM}}\right)$ development," in Proceedings of the American Helicopter Society International 32nd Annual Forum, 1976.
[2] A. Bagai, "Aerodynamic design of the X2 technology demonstrator $^{\mathrm{TM}}$ main rotor blades," in Proceedings of the American Helicopter Society International 64th Annual Forum, 2008.

[3] R. Blackwell and T. Millott, "Dynamics design characteristics of the Sikorsky X2 technology ${ }^{\mathrm{TM}}$ demonstrator aircraft," in Proceedings of the American Helicopter Society 64th Annual Forum, 2008.

[4] W. Johnson, "Influence of lift offset on rotorcraft performance," in Proceedings of the American Helicopter Society Specialist's Conference on Aeromechanics, 2008.

[5] W. Johnson, CAMRAD II: Comprehensive Analytical Method of Rotorcraft Aerodynamics and Dynamics, Johnson Aeronautics, Palo alto, Calif, USA, 2012.

[6] H. A. Saberi, M. Khoshlahjeh, R. A. Ormiston, and M. J. Rutkowski, "RCAS overview and application to advanced rotorcraft problems," in Proceedings of the American Helicopter Society Fourth Decennial Specialists Conferenceon Aeromechanics, 2004.

[7] G. Jacobellis, F. Gandhi, and M. Floros, "A physics-based approach to trim optimization of coaxial helicopters in highspeed flight," in Proceedings of the American Helicopter Society International 71st Annual Forum, 2015.

[8] A. J. Ruddell, "Advancing blade concept (ABC) technology demonstrator," USAAVRADCOM-TR-81-D-5, 1981.

[9] C. P. Coleman, "A survey of theoretical and experimental coaxial rotor aerodynamic research," NASA Technical Paper TP-3675, 1997.

[10] J. S. Bauchspies, W. R. Bryant Jr., and W. E. Simpson, "Trade off analysis of technology needs for public service helicopters," NASA Contractor Report 3927 ORI TR-2459, 1958.

[11] D. S. Jenney, "ABC ${ }^{\mathrm{TM}}$ aircraft development status," in Proceedings of the European Rotorcraft and Powered Lift Aircraft Forum, 1980.

[12] J. O'Leary and W. Miao, "Design of higher harmonic control for the $\mathrm{ABC}^{\mathrm{TM}}$," in Proceedings of the American Helicopter Society Mideast Region National Specialists Meeting on Rotor System Design, 1980.

[13] F. F. Felker III, "Performance and loads data from a wind tunnel test of a full-scale, coaxial, hingeless rotor helicopter," NASATM-81329, 1981.

[14] W. Johnson, A. M. Moodie, and H. Yeo, "Design and performance of lift-offset rotorcraft for short-haul missions," in Proceedings of the American Helicopter Society Future Vertical Lift Aircraft Design Conference, 2012.

[15] W. Johnson, "Rotorcraft dynamics models for a comprehensive analysis," in Proceedings of the American Helicopter Society 54th Annual Forum, 1998.

[16] J. W. Lim, M. J. Smith, S. N. Jung et al., "An assessment of comprehensive code prediction state-of the-art using the HART II international workshop data," in Proceedings of the American Helicopter Society 68th Annual Forum Technology Display, 2012.

[17] J. W. Lim, K. W. McAlister, and W. Johnson, "Hover performance correlation for full-scale and model-scale coaxial rotors," Journal of the American Helicopter Society, vol. 54, no. 3, Article ID 032005, 2009.

[18] W. A. Pleasants, "A rotor technology assessment of the advancing blade concept," AVRADCCM Technical Report 82-A-18, 1983.

[19] N. Simon, The Foundations Helicopter Flight, ButterworthHeinemann, 1st edition, 1994. 


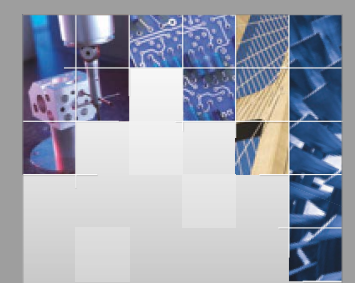

\section{Enfincering}
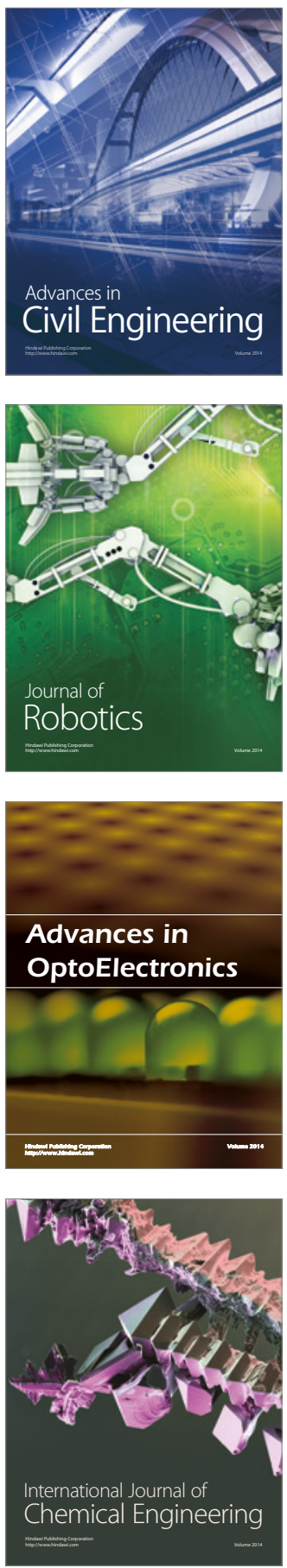

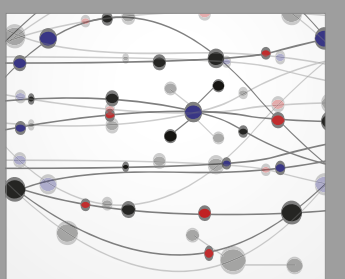

The Scientific World Journal

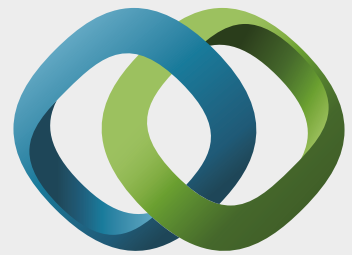

\section{Hindawi}

Submit your manuscripts at

https://www.hindawi.com
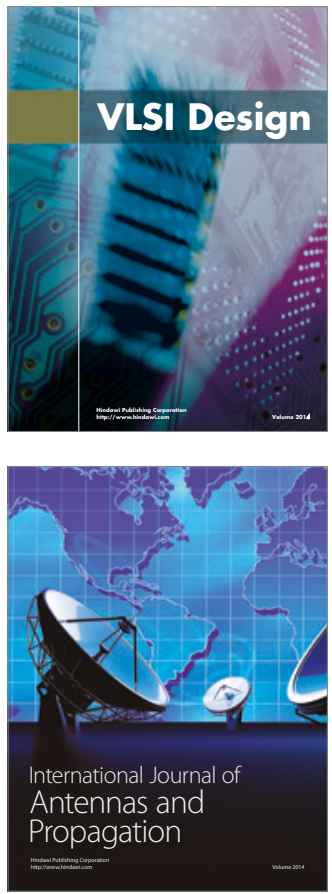

\section{Rotating}

Machinery
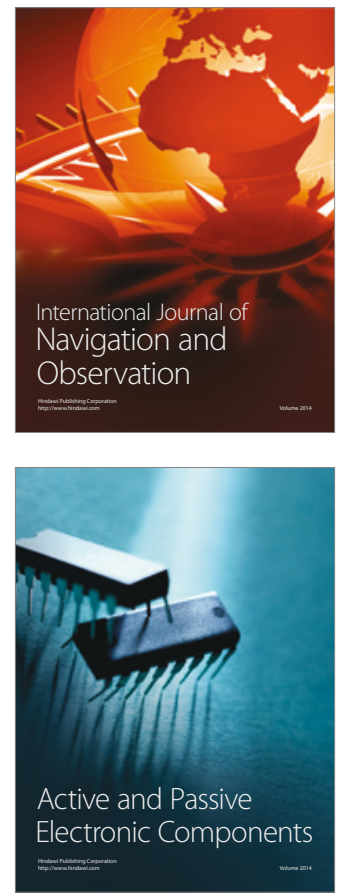
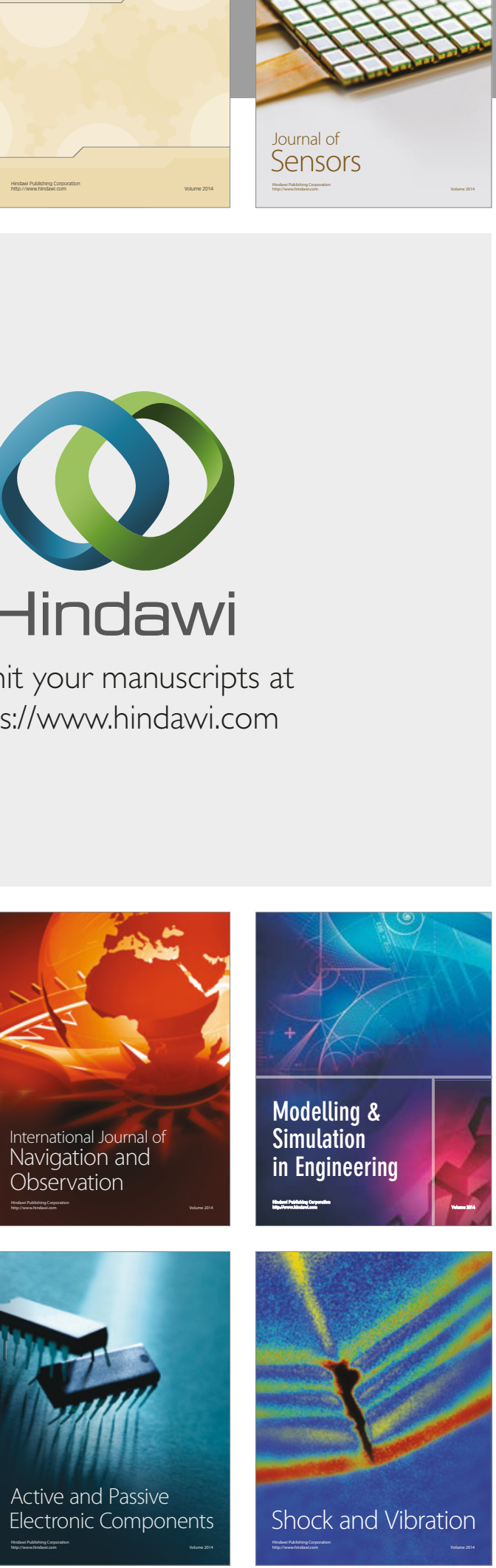
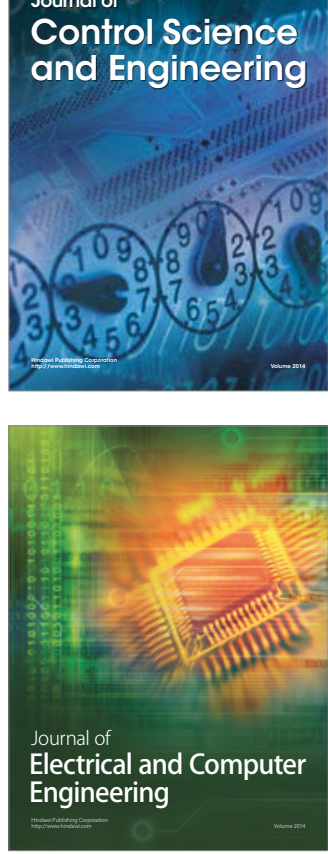

Distributed

Journal of

Control Science

and Engineering
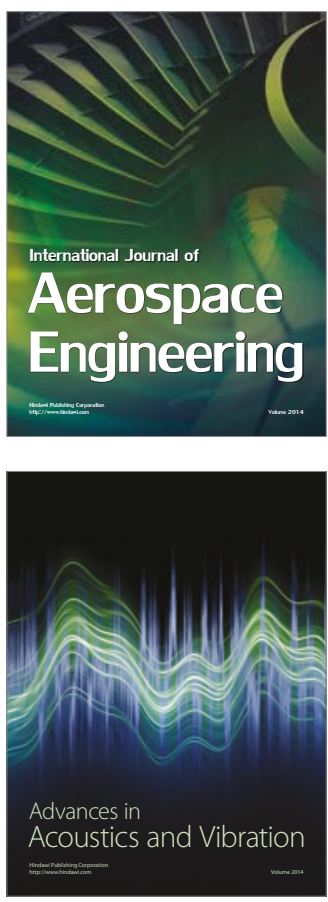

Sensor Networks 